\title{
Antiproliferative Effect of Lactobacillus helveticus and Low Dose Gamma Radiation on Mammary Carcinogenesis
}

\author{
M. Abdalla, E. Mahdy, E. Ali*, S. El-Sonbaty** and M. Hussien \\ Chemistry Dept., Faculty of Sciences, Helwan University, Egypt, \\ *Radiation Biology Dept. and **Radiation Microbiology Dept., \\ National Canter for Radiation Research and Technology (NCRRT), \\ P. O. Box; 29 Nasr City, Egypt.
}

TMMUNOTHERAPY plays an important role in cancer Iprevention and treatment. This study was aimed to investigate the role of milk fermented by Lactobacillus helveticus (L. helveticus) and low dose of gamma radiation $(0.25 \mathrm{~Gy})$ as protector and immunotherapy for breast cancer.

Female rats were divided into 7 groups, control group, fermented milk with L. helveticus (FM) Group, whole body gamma irradiated group, injected with $17 \beta$-estradiol (E2) group, FM and injected with E2 group, gamma irradiation and E2 group and FM then exposed to gamma radiation and injected with E2.

Results showed that, E2 caused a reduction in the percentage of cluster of differentiation 4 (CD4) and cluster of differentiation 8 (CD8), an decrease in glutathione (GSH), malonaldehyde (MDA), nitric oxide (NO) levels and glutathione peroxidase (GPx), but increase in catalase (CAT) and superoxide dismutase (SOD) activities as well as an increase in the proliferation marker Ki-67 (Antigen KI-67 also known as Ki-67), with hyperplasia appeared in the histological examinations of mammary tissue epithelium. FM with or without gamma radiation increased $\mathrm{CD} 4$ and $\mathrm{CD} 8$ count, ameliorated GSH, MDA and NO levels, GPx, CAT and SOD activities and reduced Ki-67 percentage. Histological study showed normal breast tissue. This study demonstrated that FM and gamma radiation (0.25 Gy) induced immunoregulatory and antioxidant capacity in preventing carcinogenic effect of $\mathrm{E} 2$ on breast tissue.

Keywords: $17 \beta$-estradiol, $\gamma$-rays, breast cancer, L. helveticus.

Breast cancer is one of the most common cancers in women and many dietary factors are related with it either positively or negatively (Kim et al., 2011). Estrogens have been implicated to be complete carcinogens through a mechanism involving oxidative stress in the kidney, liver and breast tissues (De Le-Blanc et al., 2005). 
Data from epidemiological and experimental studies have also indicated that the ingestion of certain lactic acid bacteria (LAB) strains or their fermented dairy products might alleviate the risk of certain types of cancers and inhibit tumours growth (Liu and Pan, 2010). Probiotic organisms and LAB in fermented milks are beneficial to the immune system and increase the resistance to neoplasia and infections. For these and other reasons, there is a steady increase in the consumption of fermented dairy products containing viable microorganisms (De Le-Blanc et al., 2005 and Kato, 2000).

Cellular detoxification, DNA reduction, decreasing the probability of neoplastic transformation, tumour growth delay, antimetastatic effects and sensitization of tumour could be achieved via exposure to low doses of ionizing radiation (Hosoi, 2006 and Redpath and Elmore, 2007). Such exposures may also enhance immune reactions and attenuate harmful effects of higher doses of radiation (Safwat, 2000 and Safwat et al., 2003). These may explain the low incidence of leukaemia and some solid tumours as reported among nuclear workers and in the survivors of the Hiroshima and Nagasaki bombings whose absorbed doses did not exceed 0.25 Gy (Katayama et al., 2002 and Matanoski, et al., 1990). Previous studies have shown that compounds released during milk fermentation by $L$. helveticus are implicated to have antitumor effect of fermented milk (De Le-Blanc et al., 2005). The studies on the beneficial effects of fermented products in the prevention of different types of cancer such as colon cancer showing an inhibition of tumour growth during cyclical yoghurt feeding inhibited promotion and progression of the experimental intestinal tumour (Brady et al., 2000 and De Le-Blanc et al., 2005). Thus, this study was aimed to evaluate the effects of FM consumption on the immune system, antioxidant responses and a tumour marker of E2 dependent breast hyperplasia.

\section{Materials and Methods}

\section{Preparation of fermented milk by L. helveticus}

L. helveticus ATCC 15009 was obtained from Microbiological Resources Canter (MIRCEN, Cairo, Egypt). Milk used was sterile non-fat milk by autoclaving at $115{ }^{\circ} \mathrm{C}$ for $15 \mathrm{~min}$ and yeast extract $(0.4 \%)$ was added to the milk used to grow $L$. helveticus before autoclaving. Sterile milk was inoculated with L. helveticus $(2 \% \mathrm{vol} / \mathrm{vol})$ and incubated statically at $37{ }^{\circ} \mathrm{C}$ for $17 \mathrm{~h}$. Fermented 
milk had a concentration of $1 \times 10^{9} \mathrm{cfu} / \mathrm{ml}$ at the end of the fermentation period (De Le-Blanc et al., 2005).

\section{Animals and treatments}

Female adult Wister albino rats weighing $100 \pm 10 \mathrm{~g}$ were housed in the animal house of NCRRT, Egypt. Animals were cared in accordance with the standards outlined in Guide for the Care and Use of Laboratory Animals (DHHS publication 85-23) and received food and water ad libitum. Animals were divided into 7 groups $(\mathrm{n}=8)$. Control, rats were received $1 \mathrm{ml}$ of $0.9 \%$ saline by gavages, FM group, rats received FM $1 \mathrm{ml} / \mathrm{kg}$ body wt/ day by gavages, radiated group, rats were exposed to whole body of 0.25 Gy of $\gamma$-rays, E2 group, rats were inter peritoneum (i.p.) injected once with E2 $(50 \mathrm{mg} / \mathrm{kg}$ body wt), Sigma Chemical Co. (St. Louis, MO, USA), E2+ FM group, rats were received $\mathrm{FM} 1 \mathrm{ml} / \mathrm{kg}$ body wt/ day, for 15 days then injected with E2 $(50 \mathrm{mg} / \mathrm{kg}$ body weight ) and continued receiving FM, Group 6 (E2+radiation): rats were exposed once to gamma radiation $(0.25 \mathrm{~Gy})$ and injected with E2 $(50 \mathrm{mg} / \mathrm{kg}$ body wt) and E2+ radiation+ FM group, rats were received FM for 15 days and exposed once to $\gamma$-rays $(0.25 \mathrm{~Gy})$ then injected once with E2 $(50 \mathrm{mg} / \mathrm{kg}$ body wt) and continued receiving FM for 28 days.

\section{Irradiation}

Whole-body gamma irradiation was performed at the NCRRT, using ${ }^{137} \mathrm{Cs}$ Gamma Cell-40 biological irradiator. Animals were exposed to a single dose of $0.25 \mathrm{~Gy} \gamma$-rays at a dose rate of $0.46 \mathrm{~Gy} / \mathrm{min}$.

\section{Antioxidant assays}

Antioxidant parameters were measured in the liver homogenate $(10 \%$ in 0.9 $\%$ saline). Tissue content of glutathione (GSH) was measured calorimetrically according to the method described by Beutler et al. (1963). The activity of glutathione peroxidase (GPx) was measured calorimetrically according to the method described by Gross et al. (1967). The activity of superoxide dismutase (SOD) was measured according to the method described by Minami and Yoshikawa (1979) and catalase (CAT) activity was measured calorimetrically according to the method described by Sinha (1972). Lipid peroxide concentration was determined by measuring the Malonaldialdahyde (MDA) end product content described by Yoshioka et al. (1979). Nitric oxide (NO) was determined according to Miranda et al. (2001).

Egypt. J. Rad. Sci. Applic., Vol. 26, No. 1-2 (2013) 


\section{Determination of CD4, CD8 and Ki-67}

FACS calibar flow cytometer in Mansoura Children Hospital was used (Becton Dickinson, sunnyvale, CA, USA) equipped with a compact air cooked low power $15 \mathrm{~m}$ watt Argon ion laser beam (488nm) was used to determine percentage of cluster of differentiation 4 (CD4) and cluster of differentiation 8 (CD8). The average number of evaluated nuclei per specimen was 20.000 and the number of nuclei scanned was 120 per second. CD4and CD8 histograms were obtained by a mathematical analysis according to Dean and Jett (1974).

Determination of cell proliferation marker (Ki-67) in breast tissue was determined using Anti-Ki-67 antigen conjugate (Monoclonal Mouse AntiHuman Ki-67 Antigen, Clone Ki-67) according to methodology described by Tribukati (1984).

\section{Evaluation of apoptosis and cell cycle analysis}

Flow cytometric analysis was performed for cell cycle analysis and evaluation of apoptosis via DNA stained with propidium iodide. As the DNA content is duplicated prior to cell division, mathematical models can estimate the percentage of cells in different phases of the cell cycle (G0/1, S, G2/M).

Data analysis was conducted using DNA analysis program MODFIT (verity software house, Inc. Topsham, ME 04086 USA), version: 2.0.

\section{Histopathological study}

Sections of mammary glands were stained with haematoxylin and eosin (H\&E) and examined by light microscope (Banchroft et al., 1996).

\section{Statistical analysis}

The values representing mean \pm standard deviation (S.D.), values were considered statistically significant if the $P$-value was less than or equal 0.05 . Comparisons among the different groups were carried out by ANOVA tests using SPSS (statistical package for social sciences, 1999; ver.10.0).

\section{Results}

To evaluate the effect of FM and gamma radiation on antioxidant parameters, GSH level, GPx, CAT and SOD activities were assayed. The results showed that E2 injection significantly decreased GSH and CAT 
activity and significantly increased GPx and SOD activities compared to the control. Oral intake of FM and low dose of gamma radiation significantly ameliorated GSH, GPx, CAT and SOD activities, while a marked ameliorative effect in antioxidant parameters was the result of combined treatment of FM and gamma radiation in E2 treated rats compared to E2 group (Table 1).

To determine the effect of FM and gamma radiation on oxidative stress parameters in E2 treated group, lipid peroxidation as MDA and NO levels were measured. MDA and NO levels were significantly increased by E2 and ameliorated by FM intake and combined treatment of FM and gamma radiation when compared to $\mathrm{E} 2$ treated group (Table 2).

TABLE 1. Effect of fermented milk by L. helveticus and gamma radiation on GSH, GPx, CAT and SOD activities in the liver.

\begin{tabular}{|c|c|c|c|c|}
\hline Group & $\begin{array}{c}\text { GSH } \\
(\mathrm{mg} / \mathrm{g})\end{array}$ & $\begin{array}{c}\text { GPx } \\
(\mu \text { mol oxidized } \\
\text { GSH } / \mathrm{min} / \mathrm{g})\end{array}$ & $\begin{array}{c}\text { CAT } \\
\left(\mu \mathrm{M} \mathrm{H}_{2} \mathrm{O}_{2} / \mathrm{g}\right)\end{array}$ & $\begin{array}{c}\text { SOD } \\
(\mu \mathrm{g} / \mathrm{g})\end{array}$ \\
\hline Control & $30.6 \pm 1.4$ & $148 \pm 2.1$ & $101 \pm 2.8$ & $9.3 \pm 0.5$ \\
\hline FM & $32.9 \pm 1.2^{\mathrm{a}}$ & $146 \pm 2.5$ & $98.8 \pm 3.0$ & $9.2 \pm 0.5$ \\
\hline Rad & $32.7 \pm 1.6^{\mathrm{a}}$ & $147 \pm 2.0$ & $98.6 \pm 4.4$ & $9.1 \pm 0.5$ \\
\hline E2 & $26.3 \pm 1.4^{\mathrm{a}}$ & $171 \pm 2.6^{\mathrm{a}}$ & $86.6 \pm 2.9^{\mathrm{a}}$ & $12.2 \pm 0.4^{\mathrm{a}}$ \\
\hline E2+ FM & $28.5 \pm 1.8^{\mathrm{ab}}$ & $156 \pm 2.2^{\mathrm{ab}}$ & $91.6 \pm 2.7^{\mathrm{ab}}$ & $11.4 \pm 0.4^{\mathrm{ab}}$ \\
\hline E2+ Rad & $28.9 \pm 1.3^{\mathrm{b}}$ & $155 \pm 1.2^{\mathrm{ab}}$ & $92.7 \pm 1.8^{\mathrm{ab}}$ & $10.9 \pm 0.2^{\mathrm{ab}}$ \\
\hline E2+ Rad+ FM & $29.8 \pm 0.4^{\mathrm{b}}$ & $150 \pm 1.7^{\mathrm{b}}$ & $94.2 \pm 2.7^{\mathrm{ab}}$ & $10.1 \pm 0.3^{\mathrm{ab}}$ \\
\hline
\end{tabular}

Values were represented as means \pm S.D.

$\mathrm{Rad}=$ gamma irradiation .

a: Significant compared to control $(P \leq 0.05)$.

$\mathrm{b}$ :Significant compared to E2 $(P \leq 0.05)$.

TABLE 2. Effect of FM and gamma radiation on lipid peroxidation (MDA) and nitric oxide (NO) levels in the liver.

\begin{tabular}{|c|c|c|}
\hline Group & $\begin{array}{c}\text { MDA } \\
(\mu \mathrm{M} / \mathrm{g})\end{array}$ & $\begin{array}{c}\text { NO } \\
(\mathrm{nM} / \mathrm{g})\end{array}$ \\
\hline Control & $85.8 \pm 2.8$ & $6.3 \pm 0.4$ \\
\hline FM & $84.6 \pm 4.2$ & $5.4 \pm 0.4^{\mathrm{a}}$ \\
\hline Rad & $89.2 \pm 4.0$ & $5.5 \pm 0.4^{\mathrm{a}}$ \\
\hline E2 & $160.7 \pm 4.1^{\mathrm{a}}$ & $14.6 \pm 0.4^{\mathrm{a}}$ \\
\hline E2+ FM & $107.6 \pm 4.1^{\mathrm{ab}}$ & $7.5 \pm 0.4^{\mathrm{ab}}$ \\
\hline E2+ Rad & $139.0 \pm 3.8^{\mathrm{ab}}$ & $9.6 \pm 0.4^{\mathrm{ab}}$ \\
\hline E2+ Rad +FM & $94.0 \pm 3.8^{\mathrm{ab}}$ & $7.8 \pm 0.4^{\mathrm{ab}}$ \\
\hline
\end{tabular}

Legends as in Table 1. 


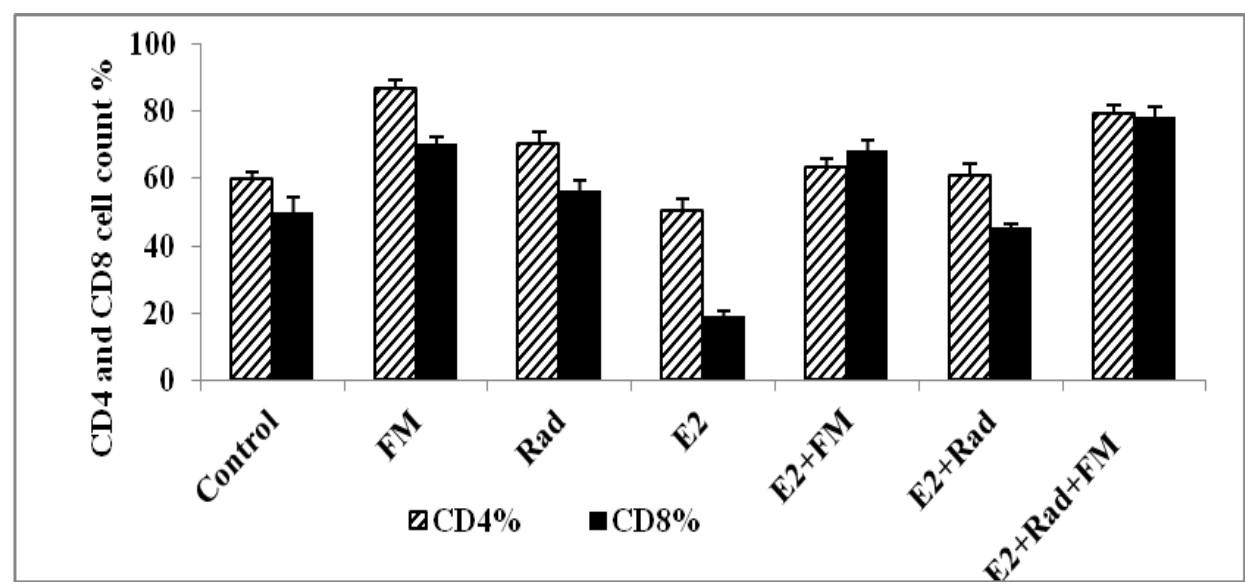

Fig. 1. Immuno-modulatory effect of FM and low dose of gamma radiation on CD4 and CD8 cell count percentage in the blood.

Legends as in Table 1.

Estradiol in E2 group significantly decreased percentage of CD4 and CD8 cells count which was then ameliorated by FM intake as compared to E2 group. FM as well as low dose of gamma radiation induced CD4 and CD8 cell count percentage compared to control (Fig.1)

To study the effects of FM and gamma radiation on cell cycle of tumour tissue induced by E2, mammary tissue cells were analyzed by flow cytometer. The results show that E2 markedly increased the cell count percentage in S and $\mathrm{M}$ phases but decreased in G0 phase when compared to that of the control. However the counts were ameliorated in $\mathrm{G} 0, \mathrm{~S}$ and $\mathrm{M}$ phases with oral intake of FM or gamma radiation and combined treatment of FM and gamma radiation (Table 3).

TABLE 3. Effect of fermented milk by L. helveticus and low dose gamma radiation on cell cycle in mammary gland of $\mathrm{E} 2$ injected group.

\begin{tabular}{|c|c|c|c|}
\hline Group & Go\% & S \% & M \% \\
\hline Control & $82.7 \pm 0.8$ & $5.8 \pm 0.9$ & $1.9 \pm 0.9$ \\
\hline FM & $84.7 \pm 0.8^{\mathrm{a}}$ & $9.6 \pm 0.7^{\mathrm{a}}$ & $3.8 \pm 0.8^{\mathrm{a}}$ \\
\hline Rad & $82.4 \pm 0.6$ & $7.5 \pm 0.6^{\mathrm{a}}$ & $1.2 \pm 0.5$ \\
\hline E2 & $52.4 \pm 0.6^{\mathrm{a}}$ & $19.5 \pm 0.6^{\mathrm{a}}$ & $8.8 \pm 0.8^{\mathrm{a}}$ \\
\hline E2+FM & $79.4 \pm 0.6^{\mathrm{ab}}$ & $10.3 \pm 0.5^{\mathrm{ab}}$ & $5.5 \pm 0.6^{\mathrm{ab}}$ \\
\hline E2+Rad & $67.8 \pm 0.8^{\mathrm{ab}}$ & $8.8 \pm 0.9^{\mathrm{ab}}$ & $4.3 \pm 0.6^{\mathrm{ab}}$ \\
\hline E2+Rad+FM & $84.6 \pm 0.7^{\mathrm{ab}}$ & $8.7 \pm 0.8^{\mathrm{ab}}$ & $3.6 \pm 0.5^{\mathrm{ab}}$ \\
\hline
\end{tabular}

Legends as in Table 1 .

Egypt. J. Rad. Sci. Applic., Vol. 26, No. 1-2 (2013) 
Estradiol induced proliferation marker Ki-67 percentage and apoptosis, FM significantly reduced Ki-67 marker but with an increase in apoptotic thus causing reduction in growth index when compared to the E2 group, while combined treatment of FM with low dose of gamma radiation markedly caused reduction in Ki-67 marker with the same growth index as that of FM alone (Fig.2).

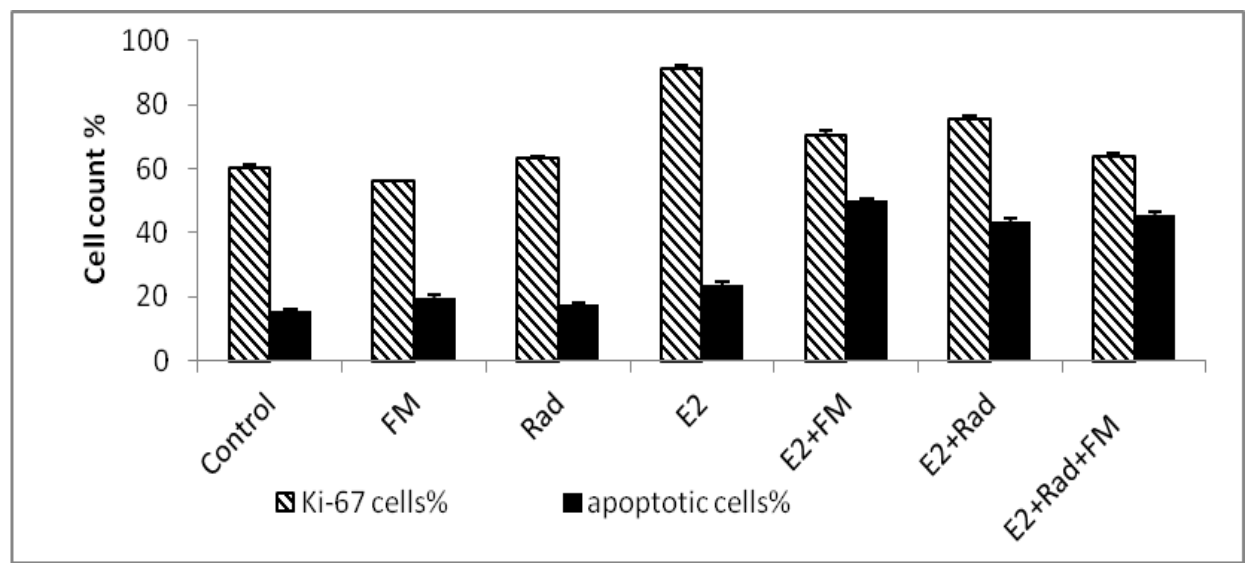

Fig. 2. Effect of fermented milk by L. helveticus and low dose gamma radiation on Ki-67 and apoptotic marker.

Legends as in Table 1.

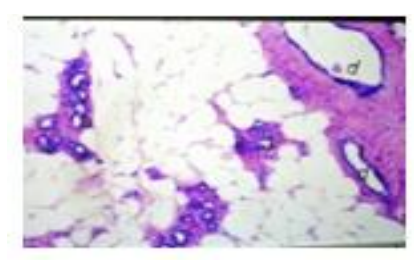

(A)

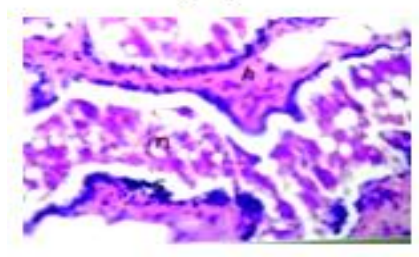

(D)

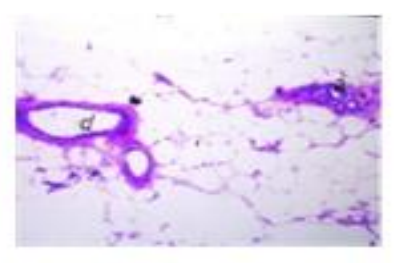

(B)

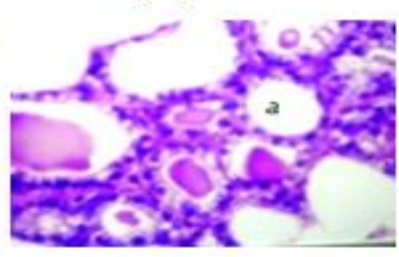

(E)

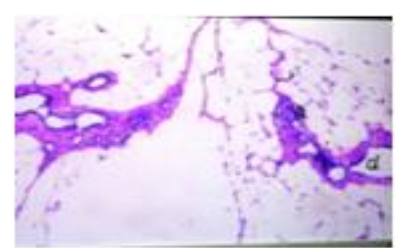

(C)

Fig. 3. Histological study of mammary gland tissue of female rats: (A) control group (40x), (B) FM group (40x), (C) gamma radiated group (40x), (D) E2 group $(160 x), F M+$ radiated group+ E2 (160x). a: acini and d: lactiferous ducts.

Egypt. J. Rad. Sci. Applic., Vol. 26, No. 1-2 (2013) 
Histopathological study by light microscope showed that healthy mammary gland of female rat was distinguished with acini and lactiferous ducts. Mammary gland of FM treated and gamma irradiated rats showed no alteration with normal histological structure of the acini and lactiferous ducts were observed. E2 caused dysplastic and anaplastic alterations associated with necrosis, also there was hyperplasia in the lining epithelium of the lactiferous duct. Rats supplemented with FM before and after E2 injection with low radiation exposure showed active acini and duct system and well differentiated lining epithelium (Fig.3).

\section{Discussion}

Spontaneous tumours frequently express antigens that can be recognized by the immune system. Specific CD4 with CD8 cells can reject tumours (Klein et al., 2003). Numerous research studies have focused on probiotics anticancer property exerting resistance to neoplasia and infections (Kato, 2000). Data from epidemiological and experimental studies have also indicated that the ingestion of certain LAB strains or its fermented dairy products might alleviate the risk of certain types of cancers and inhibit the growth of tumours (Liu and Pan, 2010).

Absorption of low doses of ionizing radiation may stimulate cellular detoxification and repair mechanisms leading to reduction of the DNA damage even below the spontaneous level and decreasing the probability of neoplastic transformation (Redpath and Elmore, 2007). Such low dose exposures may also enhance immune reactions of the organism and attenuate harmful effects of higher doses of radiation (Safwat, 2000 and Safwat et al., 2003). These mechanisms may explain that nuclear workers and in the survivors of the Hiroshima and Nagasaki bombings whose absorbed doses did not exceed $0.25 \mathrm{~Gy}$, were reported to have low incidence of leukaemia and some solid tumours when compared to the respective control groups (Katayama et al., 2002 and Matanoski et al., 1990).

In the present study, E2 caused significant changes in the measured antioxidant markers as reduction in GSH level and CAT activity was observed with an increase in GPx and SOD activities accompanied with a marked increase in oxidative stress markers MDA and NO levels. The induced changes in antioxidant parameters in the E2 group might be the result of a mechanism 
through which a controlled increase in reactive oxygen species (ROS) may act to potentiate growth at the expense of increasing sensitivity to DNA damage (Davies, 1999) and inducing oxidative stress resulted in elevated MDA and NO levels (Karabi et al., 2012). The decrease in the level of GSH following E2 injection might be due to oestrogen metabolites conjugate forming GSH conjugates in human breast tissue (Rogan et al., 2003). A decrease in peroxide metabolism was reported to be the result of a change in antioxidant enzyme activities or antioxidant substrates, total reduced and oxidized glutathione levels and the activities of CAT, SOD and GPx (Mense et al., 2009 and Mobley and Brueggemeier, 2004). Also oestrogen receptor-mediated mechanism was reported to be responsible for changes in all of the enzymes studied. According to Nishio and Watanabe (1997), significant increase in SOD and GPx activities and decrease in total GSH level and CAT activity is consistent with the observed decrease in cellular peroxide metabolism.

It is well documented, that antioxidants play an important role in ameliorating the damaging effects of oxidative stress on cells. According to our findings, oral administration of FM before and after E2 injection accompanied with low dose of radiation normalized antioxidant enzymes of GPx, CAT and SOD activities and GSH level and also normalized stress markers of MDA and NO levels. This could be attributed to potent antioxidant activity and free radical scavenging capability of FM due to antioxidant property of LAB. Therefore the LAB strains are able to decrease the risk of ROS accumulation through food ingestion and also to degrade the superoxide anion and hydrogen peroxide (Liu and Pan, 2010). The results support the role of FM in scavenging free radicals and its antioxidant properties. Lactobacillus species have been reported to play a significant role in the production of bioactive peptides in fermented dairy products by showing a significant increase in radical scavenging activity. Lactobacillus may be used to combat oxidative stress by involving in cholesterol metabolism through several anti-oxidative mechanisms: CAT, glutathione-system-related compounds and SOD, attenuating proliferation caused by ROS (Ramesh et al., 2012) and reducing oxidative stress parameters such as NO (Fernanda et al., 2012).

Exposure to low dose of gamma radiation stimulates cellular metabolic activities such as antioxidant activities; a phenomenon termed as radiation Egypt. J. Rad. Sci. Applic., Vol. 26, No. 1-2 (2013) 
hormesis which can cause an increase in GSH level in the spleen 4 hours after irradiation in mice (Liu, 1996) and might be effective for the prevention of various ROS-related diseases and exerts a protective effect upon cells and whole animals (Otsuka et al., 2006).

In the present study, E2 markedly inhibited the production of $\mathrm{T}$ cells represented by reduced CD4 and CD8 counts which were then ameliorated by oral administration of FM or exposure to gamma radiation and markedly normalized by the combined treatment of FM and gamma radiation.

It was reported that $\mathrm{E} 2$ caused a reduction in $\mathrm{CD} 4$ and $\mathrm{CD} 8 \mathrm{~T}$ cells number in rats (Kim et al., 2013). Oral administration of fermented milk induced the CD4 and CD8 percentage (De Le-Blanc et al., 2005), while exposures to low doses of ionizing radiation enhanced CD4 and CD8 production in the thymus and CD8 T cells in the spleen (Ina and Sakai, $2004 \&$ 2005a \& 2005b) hence increased the natural killing activity post-irradiation with reduction in the percentage of B cells in blood lymphocytes concomitant with an increase in helper T cell population (Kojima, 2006).

In this study, analysis of cell cycle by flow cytometry showed that the E2 markedly increased the cell population at $\mathrm{S}$ and $\mathrm{M}$ phases which were inhibited by the FM treatment as cell cycle was arrested at $\mathrm{S}$ and $\mathrm{M}$. Exposure to gamma radiation caused cell arrested at $\mathrm{S}$ phase. These effects were markedly ameliorated by the combined treatment of FM and gamma- radiation. The mechanism of cancer cell growth inhibition by LAB could be related to modulation of apoptotic signalling regulated proteins (Liu and Pan, 2010).

Acquired resistance to the programmed cell death mechanism, apoptosis, is an important hallmark of cancer (Lowe et al., 2004). Antiproliferative effects of LAB in this study, was exerted via the induction of apoptosis, necrosis and growth inhibitory effects, which was also reported by Kim et al., (2003). Fermented milk by $L$. helveticus has an antiproliferative effect on breast cancer cells. However, the precise mechanism by which LAB exerts its anticancer effects remains unknown (Liu and Pan, 2010). Combined treatment of FM with exposures to low level of gamma rays may suppress further the development and progression of tumours which can be associated with stimulation of anti-neoplastic functions of the immune system by irradiation (Nowosielska et al., 2012).

Egypt. J. Rad. Sci. Applic., Vol. 26, No. 1-2 (2013) 
Ki-67 marker is frequently measured as a marker of proliferative activity and a possible dynamic marker of tumour treatment efficacy. In the present study Ki-67 was evaluated as prognostic factor and monitoring marker during the treatment. We have demonstrated that E2 induced preneoplastic changes by elevated $\mathrm{Ki}-67$ in the breast in addition to histological analysis as preneoplastic and neoplastic changes, which were ameliorated by FM or low dose of gamma radiation or combined treatment of both.

Apoptosis has been consistently reported to be positively correlated with Ki-67 (Lipponen, 1999). In the present study, tumour growth index was markedly reduced by FM, gamma radiation and combined treatment of FM and gamma radiation. The cell turnover or growth index is an index based on the ki67 apoptosis ratio developed to approximate the contribution that these two factors may have on tumour growth, thus it can be used as an early marker of response to treatment in primary therapy of breast cancer (Bundred et al., 2002 and Cleator et al., 2002). Low dose total body irradiation showed antitumor effects which could be explained by immune enhancement, induction of apoptosis, and intrinsic hypersensitivity to low dose of radiation and it is effective as chemotherapy (Hosoi, 2006).

In conclusion our results suggest that $L$. helveticus can be used as adjuncts in fermentation of food which is the potential candidate for the prevention of breast cancer when combined with low doses of gamma radiation leading to inhibition of tumour growth.

\section{References}

Banchroft, J., Stevens, A. and Turner, R. (1996) Theory and practice of histological techniques. $4^{\text {th }}$ Ed. Churchil Livingstone, New york, London, San Francisco, Tokyo.

Beutler, E., Duron, O. and Kelly, B. (1963) Improved method for determination of blood glutathione. J. Lab. Clin. Med., 61, 882.

Brady, L., Gallaher, D. and Busta, F. (2000) The role of probiotic cultures in the prevention of colon cancer. J. Nutr., 130, 410S.

Bundred, N. J., Anderson, E., Nicholson, R. I., Dowsett, M., Dixon, M., Robertson, J. F. (2002) Fulvestrant, an estrogen receptor downregulator, reduces cell turnover index more effectively than tamoxifen. Anticancer Res., 22, 2317.

Cleator, S., Parton, M. and Dowsett, M. (2002) The biology of neoadjuvant chemotherapy for breast cancer. Endocr. Relat. Cancer, 9, 183. 
Davies, K. (1999) The broad spectrum of responses to oxidants in proliferating cells: a new paradigm for oxidative stress. IUBMB Life, 48, 41.

De Le-Blanc, A., Matar, C., Le Blanc, N. and Perdigón, G., (2005) Effects of milk fermented by L. helveticus R389 on a murine breast cancer model. Breast Cancer Res., 7, 477.

De Le-Blanc, A., Valdéz, J. and Perdigón, G. (2004) Regulatory effect of yoghurt on intestinal inflammatory immune response. Eur. J. Inflamm., 2, 21.

Dean, P. and Jett, J. (1974) Brief note: mathematical analysis of DNA distributions derived from flow microfluorometry. J. Cell Biol., 60, 523.

Fernanda, L., Danielle, C., Lívia, C., Marisa, C., Graciela, F., Lucas, L., Elizeu, A. and Iracilda, Z. (2012) A soy-based product fermented by Enterococcus faecium and Lactobacillus helveticus inhibits the development of murine breast adenocarcinoma. Food Chem. Toxicol., 50, 4144.

Gross, R., Bracci, R., Rudolph, N., Schroeder, E. and Koche, J. (1967) Hydrogen peroxide toxicity and detoxification in the erythrocytes of newborn infants. Blood, 29, 481 .

Hosoi, Y. (2006) Antitumor effects by low dose total body irradiation. Yakugaku Zasshi, 126, 841.

Ina, Y. and Sakai, K. (2004) Prolongation of life span associated with immunological modification by chronic low-dose-rate irradiation in MRL-lpr/lpr mice. Radiat. Res., 16, 168.

Ina, Y. and Sakai, K. (2005a) Activation of immunological network by chronic lowdose-rate irradiation in wild-type mouse strains; Analysis of immune cell populations surface molecules. Int. J. Radiat. Biol., 81, 721.

Ina, Y. and Sakai, K. (2005b) Further study on prolongation of life span associated with immunological modification by chronic low-dose-rate irradiation in MRL-lpr/lpr mice: effects of whole-life irradiation. Radiat. Res., 163, 418.

Karabi, G., Mau, B., Umesh, C., Pradipta, J. and Asru, K. (2012) The Role of Neutrophil estrogen receptor status on maspin synthesis via nitric oxide production in human breast cancer. J. Br. Cancer., 15, 181.

Katayama, H., Matsuura, M., Endo, S., Hosoi, M., Othaki, M. and Hayakawa, N. (2002) Reassessment of the cancer mortality risk among Hiroshima atomicbomb survivors using a new dosimetry system, ABS2000D, compared with ABS93D. J. Radiat. Res., 43, 53.

Kato, I. (2000) Antitumor activity of lactic acid bacteria. In Probiotics 3: Immunomodulation by the Gut Microflora and Probiotics. Edited by Fuller R, Perdigón G. London: Kluwer Academic Publishers, p.115.

Kim, E., Willett, W., Fung, T., Rosner, B. and Michelle, D. (2011) Holmes Diet quality indices and postmenopausal breast cancer survival. Nutr. Cancer., 63, 38.

Egypt. J. Rad. Sci. Applic., Vol. 26, No. 1-2 (2013) 
Kim, J., Woo, H., Kim, Y., Kim, K. and Lee, H. (2003) Cell cycle dysregulation induced by cytoplasm of Lactococcus lactis ssp lactis in SNUC2A, a colon cancer cell line. Nutr. Cancer, 46, 197.

Kim, S., Jeong, H., Woo, O., Seo, J., Kim, A., Lee, E., Shin, S., Kim, Y., Kim, J. and Park, K. (2013) Tumor-infiltrating lymphocytes, tumor characteristics and recurrence in patients with early breast cancer. Am. J. Clin. Oncol., 36, 224.

Klein, L., Trautman, L., Psarras, S., Schnell, S., Siermann, A., Liblau, R., von Boehmer, H. and Khazaie, K. (2003) Visualizing the course of antigen-specific CD8 and CD4 T cell responses to growing tumor. Eur. J. Immunol., 33, 806.

Kojima, S. (2006) Induction of glutathione and activation of immune functions by low dose, whole body irradiation with gamma-rays. Yakugaku Zasshi, 126, 849.

Lipponen, P. (1999) Apoptosis in breast cancer: Relationship with other pathological parameters. Endocr. Relat. Cancer., 6, 13.

Liu, C. and Pan, T. (2010) In vitro effects of lactic acid bacteria on cancer cell viability and antioxidant activity. J. Food Drug Anal., 18, 77.

Liu, S. (1996) Radiation hormesis with low level exposures. Science Press, Beijing, p. 250.

Lowe, S., Cepero, E. and Evan, G. (2004) Intrinsic tumor suppression. Nature, 432, 307.

Matanoski, G., Santos-Burgoa, C. and Schwartz, L. (1990) Mortality of a cohort of workers in the styrene-butadiene polymer manufacturing industry (19431982). Environ. Health. Perspect., 86, 107.

Mense, S., Singh, B., Remott, F., Liu, X. and Bhat, H. (2009) Vitamin C and anaphthoflavone prevent estrogen-induced mammary tumors and decrease oxidative stress in female ACI rats. Carcinogenesis., 30, 1202.

Minami, M. and Yoshikawa, H. (1979) A simplified assay method of superoxide dismutase activity for clinical use. Clin. Chim. Acta., 92, 337.

Miranda, K. M., Espey, M. G. and Wink, D. A. (2001) A rapid simple spectrophotometric method for simultaneous detection of nitrate and nitrite. Nitric Oxide, 5, 62.

Mobley, J. and Brueggemeier, R. (2004) Estrogen receptor-mediated regulation of oxidative stress and DNA damage in breast cancer. Carcinogenesis, 25, 3.

Nishio, E. and Watanabe, Y. (1997) Transforming growth factor beta is a modulator of platelet-derived growth factor action in vascular smooth muscle cells a possible role for catalase activity and glutathione peroxidase activity. Biochem. Biophys. Res. Commun., 232, 1.

Nowosielska, E., Cheda, A. and Wargocka, J. (2012) Effect of low doses of low-let radiation on the innate antitumor reactions in radioresistant and radiosensitive mice. Dose-Response., 10, 500.

Otsuka, K., Koana, T., Tauchi, H. and Sakai, K. (2006) Activation of antioxidative enzymes induced by low-dose-rate whole-body $\gamma$-irradiation: Adaptive response in terms of initial DNA damage. Radiat. Res., 166, 474.

Egypt. J. Rad. Sci. Applic., Vol. 26, No. 1-2 (2013) 
Ramesh, V., Rajesh, K., Singh, J. and Kaushik, B. (2012) Comparative evaluation of selected strains of lactobacilli for the development of antioxidant activity in milk. Dairy Sci. Technol., 92, 179.

Redpath, J. and Elmore, E. (2007) Radiation-induced neoplastic transformation in vitro, hormesis and risk assessment. Dose-Response., 5, 123.

Rogan, E., Badawi, A., Devanesan, P., Meza, J., Edney, J., West, W., Higginbotham, S. and Cavalieri, E. (2003) Relative imbalances in estrogen metabolism and conjugation in breast tissue of women with carcinoma potential biomarkers of susceptibility to cancer .Carcinogenesis, 24, 697.

Safwat, A. (2000) The role of low-dose total body irradiation in treatment of nonHodgkin's lymphoma: a new look at an old method. Radiother. Oncol., 56, 1.

Safwat, A., Bayoumy, Y., El-Sharkawy, N., Shaaban, K., Mansour, O. and Kamel, A. (2003) The potential palliative role and possible immune modulatory effects of low-dose total body irradiation in relapsed or chemo-resistant nonHodgkin's lymphoma. Radiother Oncol., 69, 33.

Sinha, A. (1972) Colorimetric assay of catalase. Anal. Biochem., 47, 389.

Tribukati, B. (1984) Clinical DNA flow cytometry. Med. Oncol. Tumor Pharmacothue., 1, 211 .

(Received: 12/08/2013;

accepted: 22/09/2013)

Egypt. J. Rad. Sci. Applic., Vol. 26, No. 1-2 (2013) 


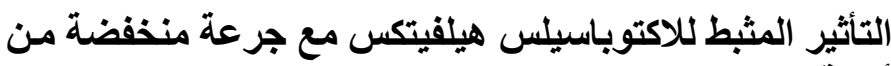

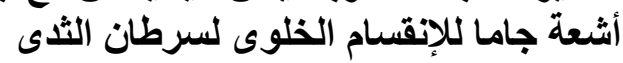

مهجة عبد الله و السيد المهلى و ايمان نعمان علي* و سوسن السنباطى** و منة الله حسين مئه عيد

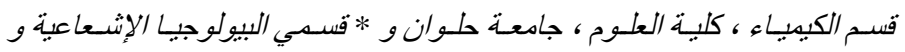

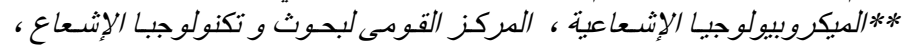

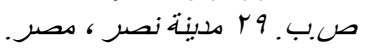

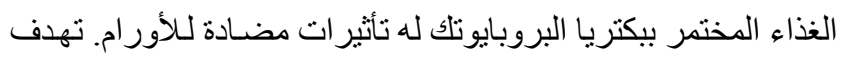

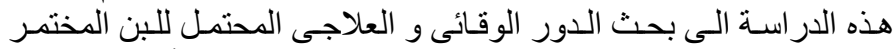

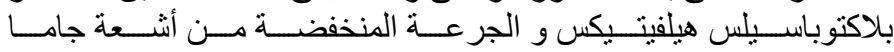

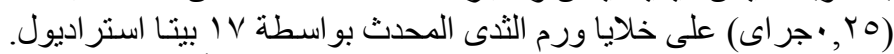

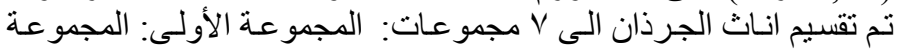

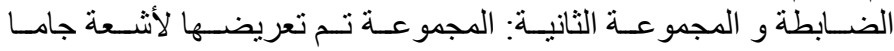

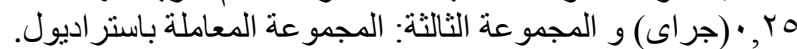

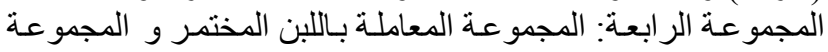

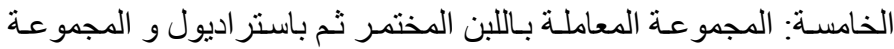

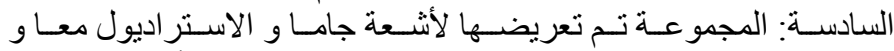

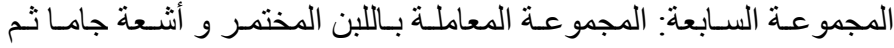
و أوضحت النتائج أن الاستر اديول له تأثير مثبط على مستوى الجهاز باسنر اديول.

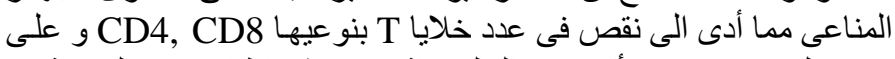

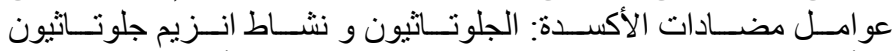

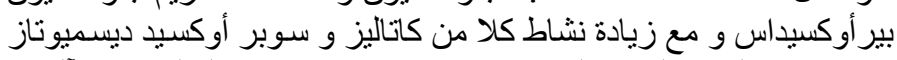

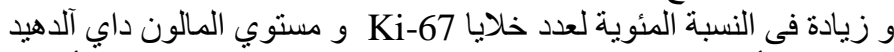

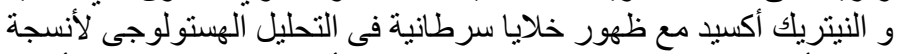

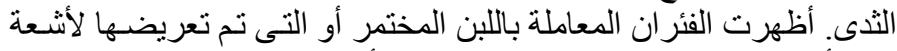

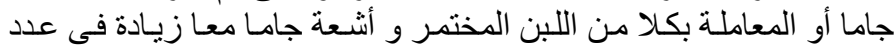

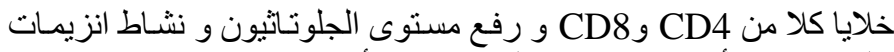

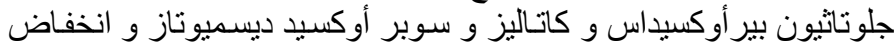

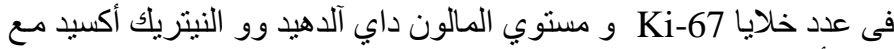

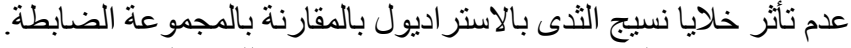

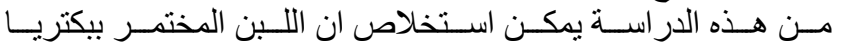

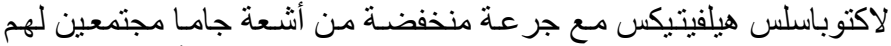

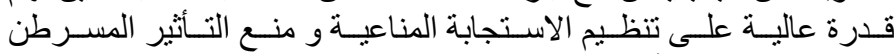

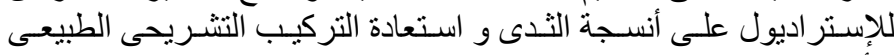
للأنسجة بالمقارنة بالمعاملات الاخرى.

Egypt. J. Rad. Sci. Applic., Vol. 26, No. 1-2 (2013) 